\title{
Study on the Incubation and Industrialization of Cultural and Creative Products of Colleges and Universities in the Perspective of "Public Entrepreneurship and Mass Innovation"
}

\author{
Fazhong Hu \\ Chengdu Normal College, Chengdu, China \\ Email: hfz_616@163.com
}

How to cite this paper: Hu, F.Z. (2019) Study on the Incubation and Industrialization of Cultural and Creative Products of Colleges and Universities in the Perspective of "Public Entrepreneurship and Mass Innovation". Open Journal of Social Sciences, 7, 368-380.

https://doi.org/10.4236/jss.2019.77031

Received: June 10, 2019

Accepted: July 27, 2019

Published: July 30, 2019

Copyright @ 2019 by author(s) and Scientific Research Publishing Inc. This work is licensed under the Creative Commons Attribution International License (CC BY 4.0).

http://creativecommons.org/licenses/by/4.0/

\begin{abstract}
In the perspective of "public entrepreneurship and mass innovation", this paper discusses the incubation and industrialization of cultural and creative products of colleges and universities, and the mechanism related to it. On the basis of the analysis on the current status and development trend of cultural and creative industry, cultural and creative industry and China's cultural and creative industry, this paper clarifies such characteristics for the industrialization of cultural and creative products as connection, systematicness and aggregation, and puts forward feasible strategies against the existing problems of the incubation and industrialization of cultural and creative products in colleges and universities, which has theoretical discussion and practical guidance significance for the cultivation of domestic cultural and creative talents and in-depth promotion of national strategies for the industry.
\end{abstract}

\section{Keywords}

Public Entrepreneurship and Mass Innovation, Cultural Creativity, Incubation and Industrialization, Connection

\section{Introduction}

Since the beginning of the $21^{\text {st }}$ century, with the transformation and upgrading of national economic development and to improve confidence of culture and national soft strength, Cultural Industry Revitalization Planning was proposed in the 17th National Congress and Plan for Redoubling Cultural Industries during the "12th Five-year Plan Period" released by Ministry of Culture. Cultural in- 
dustry was confirmed to be national major economic development strategy. It was clearly declared that innovation drove economic transition and cultural industry would be constructed to be pillar industry of national economy following the strategic objective to construct cultural industry the pillar of national economy to drive the industry through innovation and transformation has been proposed in Ministry of Culture's Planning for Cultural Industry Development during the "13th Five-year Plan Period" in the 18th National Congress. The development of cultural industry became national major strategy of economic development. Developing cultural industry has become a major economic development strategy of the country. To cultivate inter-disciplinary talents, who are the core resource, has become the top priority. In this case, colleges and universities become the bridge tower for the development of culture creativity industry. Therefore, Ministry of Education has promoted a series of college and university reform policies intensively, and has clarified the development orientation and implementation path of national cultural industry in the form of policies by promulgating over 20 documents of central ministries and commissions, including Opinions of State Council on Vigorously Promoting Public Entrepreneurship and Mass Innovation Policies and Several Opinions on Deepening the Integration of Industry and Education: Talent cultivation mode must be changed by transforming the application of colleges and universities to drive and develop cultural and creative industry through innovation, cultivate inter-disciplinary talents and realize the structural upgrading of national economic development.

\section{Public Entrepreneurship and Mass Innovation and Cultural and Creative Industry}

"Public entrepreneurship and mass innovation": "Public Entrepreneurship and Mass Innovation" was first proposed by the Premier Li Keqiang in 2015 in his government work report. Shortly after that, the State Council issued Opinions of the General Office of the State Council for the Implementation of Deepening Education Reform on Innovation and Entrepreneurship in Universities and Colleges which puts forward the comprehensive deepening of reform of innovation and entrepreneurship education since 2015; popularizing innovation and entrepreneurship education in 2017; and setting up and improving the innovation and entrepreneurship education system in colleges and universities in 2020 [1]. "Public Entrepreneurship and Mass Innovation" has become the core initiative of national innovative development strategy. Public Entrepreneurship and Mass Innovation stimulates mass enthusiasm for creativity and innovation and injects energy into traditional processing industry. Colleges organize entrepreneurship competition, practice and training as carriers and construct the industrial park of culture creativity and space of mass innovation as bases to build the practice base of "Public Entrepreneurship and Mass Innovation", industry-university-research practice base and incubation zone for constructing a "dream factory of entrepreneurship" [2]. 
Being different from traditional labor-intensive manufacturing industries of heavy pollution and energy-extensive consumption, cultural creative industry is an emerging industry and product of economic globalization. With the core of creativity, it mainly depends on individuals (team) to develop and apply the elements of cultural resources by technology, creativity and industrialization, which increases additional value. An industry that main culture or cultural elements depend on development and marketing of intellectual property is emphasized. It is therefore believed "the sunrise industry in the era of integration with the global economy in the $21^{\text {st }}$ century" [3]. Meanwhile, cultural creative industry is not limited to the existing media, forms and content in cultural industry. It has been integrated into digital media, internet, big data and artificial intelligence. As an emerging industry featured by high-profit and low energy consumption, the industry is an important representative of new economy. "Originating from individual creativity, skill and talent, creativity will create fortune and employment potential after it produces and is developed into intellectual properties" [4]. The development of cultural industry is not only required by industrial structure transformation and upgrading, but also necessary for finding new economic growth points.

\section{Current Status of China's Cultural and Creative Industry of Colleges and Universities}

Upon the promulgation and implementation of Opinions for the Implementation of Deepening the Innovation and Entrepreneurship Education of Institutions of Higher Education and Opinions on Guiding Part of Regional Common Full-time Universities to Transform into Application Universities in 2015, colleges and universities nationwide lifted up the climax of transforming into application and exploring the reform of "Public Entrepreneurship and Mass Innovation" education mode actively (especially the colleges and universities that transformed into common full-time universities after 2000). Due to the restrictions of capital, technology and equipment, colleges and universities integrate resources and set up platforms utilizing their own disciplines and majors, as well as talent intelligence. Such practice application and teaching platforms as cultural and creativity industry park, innovation and entrepreneurship park, incubation park and cultural and creative R \& D center sprang up like mushrooms in the colleges and universities around the country. Many universities and colleges, especially art design universities and colleges drove the transformation of education application with cultural creativity as the breakthrough point.

Different from the traditional manufacturing and processing industry featured by intensive labor force, heavy pollution and high energy consumption, cultural and creative industry essentially lies in culture, creativity, science \& technology and knowledge and integrates different sectors. To be specific, creativity plays a crucial role in it. Colleges and universities which are dominated by youth are always where new culture and new ideas are originated and where new products 
and new lifestyle drive the trend; therefore, the aggregation and activity of the colleges and universities in terms of talent and intelligence are much higher than those of other social organizations and are advantageous naturally in terms of the R \& D of cultural and creative products (hereinafter referred to as "cultural and creative products"). The core resources needed by cultural creative industry are culture, creativity, science $\&$ technology and knowledge and they integrate different fields. To be specific, creativity plays a crucial role in it. "Industry" means the production value of industry and commerce in cooperation. It is a production of enterprization [5]. Colleges are insufficient in industrialization. Many colleges and universities have been exploring the integration of industry-university-research cooperation actively by responding to the corresponding state policies in recent years; they have improved the internal and external connected innovative talent cultivation mechanism featured by the integration of science and education, and industry and study, promoted the construction of cultural and creative industrial system by exploring the combination of theory of cultural industry, talent cultivation, program $\mathrm{R} \& \mathrm{D}$, professional skill training and social service, built academic study teams for cultural industry, cultivated high-level inter-disciplinary cultural and creative talents and stimulated the construction of ecological system of cultural creative industry.

\section{Incubation Path for Cultural and Creative Products of Colleges and Universities}

In colleges, especially the comprehensive colleges of humanities and arts, the main tasks of Public Entrepreneurship and Mass Innovation + cultural creative industry are the R \& D of cultural creative products and industrialized incubation. Many local undergraduate universities are applying or have applied integration of production and education to complete diversified cultural creative products or even incubate a batch of entrepreneurial enterprises featured with cultural creative products. They become important pushing hands which serve regional economy and cultural creative industry.

Creativity, which utilizes new technologies and combines new cultural elements, such as concept, emotion and tastes, provides brand new experiences for customers so as to realize cultural and creative value of cultural and creative products and services. In terms of form, cultural and creative products are not only real objects but also creative activities and service experience. Cultural and creative products have three attributes, i.e., culture, creativity and products and cover the features of arts, science \& technology and economy. Therefore, original and derivative cultural and creative products and those of activity all depend on creativity and its development and use. In consideration of the above, the cultural and creativity practitioners are required to not only master the cultural knowledge, creativity and technology but also know about the knowledge regarding products development and operation management. From the perspective of industry chain, cultural and creative products are completed in the same 
way with that of other products. There are three stages, including preliminary $\mathrm{R}$ $\& \mathrm{D}$, sample manufacturing in middle stage and marketing \& derivative product development in later stage. The three stages are highly systematic and connected. Each of the links influences and promotes each other.

Incubation of cultural and creative products depends on a series of creative thinking activities. Problem discovery and posing are where the creativity of cultural and creative products starts and also the first step for creative thinking, i.e., the problem to be resolved and whether the problem is the demand of individual consumer or group consumers. The followings should be defined in the gradual extraction process: the product to be developed, culture proposition and creativity value point, target consumers and new market potentials, all of which are closely related to the market positioning of cultural and creative products. The preliminary incubation of cultural and creative products is featured by high intelligence aggregation and cross-border integration of professions. Colleges and universities have the conditions to carry out interdisciplinary, trans-disciplinary, cross-school and even cross-college resources integration by leveraging talents, time, space and hardware \& software. The incubation of cultural and creative products by colleges and universities is generally made via the following several ways.

\subsection{Cultural and Creative Incubator of Colleges and Universities}

Colleges and universities generally set up the organizations such as cultural and creative incubator (park), industry-university-research center or R \& D center and innovation and entrepreneurship test center by using their own assets in a region or a building or even a room to absorb some of their excellent innovation and entrepreneurship teams and R \& D programs; they also attract some cultural and creative enterprises who are granted supports such as rent, capital, technicians and tutors to cultivate entrepreneurship team, individual and program with the joint efforts. They refer to the design company's mode for the working mechanism which is much more tolerant. With studio or design workshop, students are enabled to participate in the cultural and creative programs in person and education teaching is made to be synchronous with market so that students could get familiar with working process and understand the latest industry dynamics early, and form innovation ability and the awareness of entrepreneurship.

For the incubation of cultural and creative products, colleges and universities, as the gathering place of cultural and creativity enterprises and information flow of cultural and creative industry, integrate new technology and new process creativity to cultural contents by leveraging the support from the settling enterprises such as capital and technology, production experience and market anticipation. The cultural and creative sites inside colleges and universities facilitate the participation of teachers and students and could allow colleges and universities to combine market demand with daily teaching activities to promote class 
teaching reform, cultivate the innovation and entrepreneurship atmosphere of "applying the knowledge" favorably and provide a good platform for "research, production and use" of teachers and students for colleges and universities; it finally resolves the issue of ecological construction driven by the internal innovation at the upstream of cultural and creative industry chain and its operation mechanism.

\subsection{Incubation of Studio under Program Credit System}

The specialty studios in colleges and universities are a critical platform for colleges and universities to develop practical teaching and also "mini enterprises" of cultural and creative industry. The studios are defined by space but are not restrained from the division based on the way above. One or several specialty lecturers could set up a studio or a cultural and creative product program can be developed in one or several studios jointly. In the studio teaching, the company's job responsibilities are simulated; the whole process of the program is managed by focusing on the program itself and theoretical knowledge teaching is combined with practical skills. At the same time, well experienced enterprise technicians and experts will be invited to provide guidance with specialty lecturers so as to control the risks that may happen to cultural and creative products in the late stage of the program, such as market positioning, production technology and value appraisal. Students could work independently and also coordinate with others in the studios so as to feel the atmosphere of professional practice in person, and motivate learning initiative and creativity; in one aspect, that contributes to personalized development of cultural creative products; in another aspect, the students could consider and evaluate their professional ability, employment market and industrial development prospect [6].

The credit system practice teaching of the program breaks through the traditional teaching mode and the restrictions of specialties, schools, locations and identities; an open study and learning environment featured by diversified and interdisciplinary cooperation could be set up by focusing on the program. A coordinative innovation alliance could be established by mechanism innovation to integrate the resources inside and outside colleges and universities fully and flexibly, which could help students improve their capacity of transforming the cultural and creative ideas into cultural products and carrying out preliminary commercial development and also help cultivate inter-disciplinary talents urgently needed by cultural and creative industry with originality and technical capacity; studio teaching ensures the professionalism of the second classroom teaching and is an effective way of classroom teaching introduced by program.

\subsection{Incubation of Off-Campus Training Base}

Off-campus training base shall be the creativity enterprises which are advantageous in terms of technical skills, capital equipment, product R \& D and market operation. By paying a visit to, investigating and learning in the training bases 
regularly, students could contact the enterprises' designers and production staffs, which, as a result, enables them to understand the existing production technique, production level, market form of cultural and creative products, and industrial and employment development trend directly and efficiently. It means a lot for students to build a favorable awareness of specialty, industry and occupation.

As a critical site for colleges and universities to develop production and education integrated teaching mode reform, off-campus training base could help transform students' training from consumable type to productive and product type. By associating cultural intelligence advantages of colleges and universities with cultural and creative enterprises' advantages such as technique, capital, brand and mature commercial mode, students' creativities (creative works) and works could be screened in time and efficiently and those with prospect could be transformed into products for industrial development so as to deepen the reform of classroom teaching mode. It, on the one hand, motivates enterprises' vitality of innovating new products and reduces R \& D costs and improves efficiency; on the other hand, students' creative results can be discovered, protected (intellectual properties) and developed in time and students could gain profits and even may be recruited by companies in advance due to their outstanding skills.

\subsection{Program Classroom Teaching and Contests}

Generally speaking, students gather in classroom the most prior to graduation. Program classroom teaching is the innovative teaching reform against the traditional "cramming" lecturing which emphasizes theory and ignores practice: Innovative talent cultivation mode integrating "teaching, R \& D and incubation". Program classroom teaching is aimed at incubating cultural and creative product program in the form of cultural and creative product social program or participating event and by highlighting "art + technology", setting up professional interdisciplinary innovation team and developing special and special teaching practice.

More professional or special design contests have been organized at present, both at home and abroad: The innovation and venture contests and cultural and creative design contests at all levels and of different kinds provide broad issues for college students. With "cultural and creative week", highly developed information industry and rich and diversified design interaction tools, more people agree on the idea "nothing is impossible". Students' course assignments (graduation projects), practice works and contest works and the creative works finished by lecturers and students jointly can be included in the incubation of cultural and creative products. Students could practice their creativity, capacity of project management and coordination and sensitivity for demand market effectively by finishing course assignments or contest works, which is also beneficial to cultivating students' awareness of scientific research, innovation and entrepreneurship as well as improving humanistic and technological innovation atmosphere 
of colleges and universities.

By constructing cultural creative incubator, executing the system of program credit + studio, cooperating with off-campus practice base, introducing programs in class, participating competition, taking diversified measures and sufficiently using their own resource superiorities to incubate cultural creative products, the colleges and universities have owned their important content and superiorities of the education of "public entrepreneurship and mass innovation".

\section{Industrialization Path of Cultural and Creative Products of Colleges and Universities}

Incubation of cultural and creative products is a process of finding value. Industrialization is the process of realizing value. Therefore, industrialization is the final aim of creativity [7]. The value of creative industry includes five links, i.e., generation, production, marketing, promotion and consumption. The cultural exchange among different stratums is necessary. And it is required to introduce cultural capital and use capital elements to stimulate the unceasing output of labor force element and intelligence element [8]. After one cultural and creative product is provided with creative contents with certain value, another key link to realize its value is to industrialize it, which means enriching its outward manifestation via technology, process and various media to circulate the product on market more quickly so as to obtain value.

In general, the industrialization of cultural and creative products is connected with preliminary incubation: In preliminary period, product market positioning needs to be solved. Attention shall be paid to cooperation with enterprises, governments, banks and other source-oriented institutions in middle and late stage, including capital, technology, process, art and even big data analysis; however, the above are exactly the shortages of colleges and universities. Only by expanding outside driving mechanism can the market value of cultural and creative products be maximized.

By taking the operation mechanism of the UK's creative industry as an example, it is mainly finished by the interaction and cooperation of colleges and universities with creative industry circle and scientific research institutions: colleges and universities interact and cooperate with creative industry to strengthen communication in creativity talents in order to solve the transfer and integration between creativity talents and knowledge; second, their interaction and cooperation promote technological innovation and quicken technology transfer between each other; third, their interaction and cooperation promote R \& D and technology transfer, make up for the huge difference between the two and realize the industrialization development of technology. Although the development history of cultural creative industry is short in our country, it develops rapidly with great potential. Especially, the culture creativity in colleges and universities as typical representative shows energetic innovation vitality and has created considerable social benefit and economic benefit. The cultural and creative products 
and industrial ecology in colleges and universities are becoming mature. Industrialization path becomes diversified gradually, including patent protection, transfer \& authorization, joint development or even brand establishment and self-employment.

\subsection{Media of Creative Industry}

The final step of achieving the value of creative products is generally finished by the media of creative industry, which serves as the bridge for connecting "from creativity to market" and "from market to production" links of cultural and creative products and plays an important role in promoting creativity industrialization (Figure 1).

After cultural and creative products of colleges and universities take shape, creative industry media are needed to attract manufacturers to invest, develop and produce creativity plan and transform creative ideas into tangible products or specific service for the purpose of industrializing creative result. In the process, modern industry, economy and media should be used to spread cultural and creative works more widely. Cultural and creative products could be reached by the mass finally via processing, storage and sales; creative industry media provide interaction information for subjects such as creative products developer, producer, operator, promoter, spreader and consumer. As an intermediate link that connects creative contents with the links of creative industry such as production, marketing and consumption and also a very important platform to support the success of creativity industrialization, it plays a vital role in reducing links and expenses of creative products and expanding market scope and capacity, such as associations serving trades, cultural and creative industry associations and intellectual property rights trading center; On the one hand, creative industry media propagandizes, popularizes, trades and spreads creative products systematically applying "internet+" as the superiority, so that the products can be reached to consumers via sales network in order to transform the cultural and creative products from creativity to commodities and finish the industrialization and value addition; on the other hand, industrialization extension in late stage can also be realized through brand and capitalization [9].

\subsection{Patent Protection}

The essence of cultural and creative products is about human's wisdom creating. The decisive power to promote the development of creative industry is creativity and sharing of creativity knowledge. However, as the critical intangible asset, creativity can be easily referred to and imitated. Therefore, how to protect creativity and creative products is the prerequisite and necessary conditions for ensuring a normal and orderly cultural and creative industry.

It is of great significance to protect cultural and creative products via patent application when they take shape basically or activity planning is basically completed and will be industrialized (or at the same time). The implementation and 


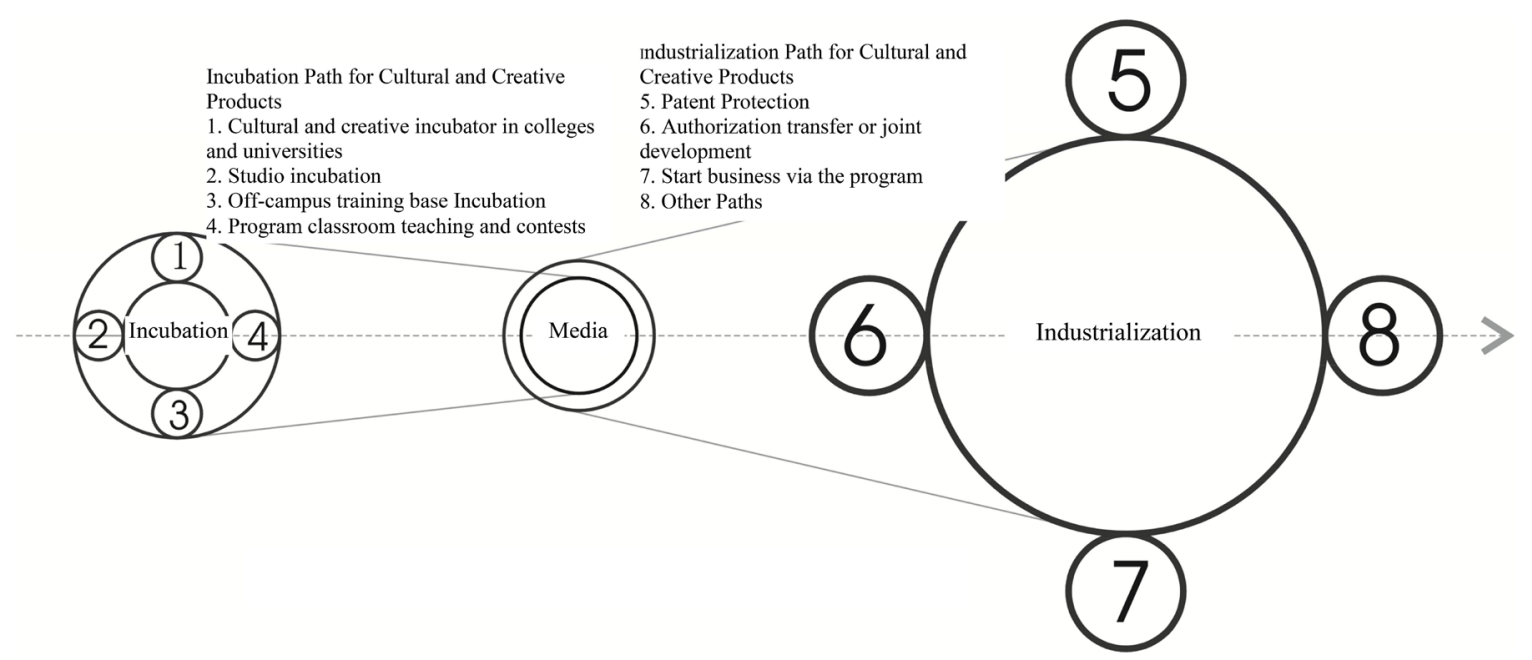

Figure 1. Schematic diagram of operation mechanism of incubation and industrialization factors of cultural and creative products.

protection of intellectual property can not only safeguard the legitimate rights and interests of creativity talents (reasonable pricing) but also ensure a healthy and stable cultural and creative industry market; what is more, it could also safeguard national security and interests largely and guarantee social solidarity and stability and orderly economic development. Therefore, intellectual property rights protection system is the foundation for the survival and key for the development of creative industry, enables individuals or enterprises to protect the creativity by transforming it into patent, trademark, brand and logo, urges cultural and creative enterprises and intermediary institutions to improve their rules and regulations and creates a legal environment for the healthy and sustainable development of cultural industry.

To encourage both enterprises and individuals to protect creativity by setting limitation or transforming it into patent, trademark, brand and logo, the government has established a special channel for receiving the application of patent enterprises to provide intellectual property protection and development of intellectual property in order to quicken the industrialization of creative results.

\subsection{Transfer Authorization or Joint Development}

The capitalization of cultural and creative industry is the requirement for the industrialization of cultural and creative industry. It not only needs government's support and protection of intellectual property but also forms the overall identification of market for the value of cultural and creative capital and property system which protects the cultural and creative capital. A team or individual can transfer the patent after finishing the incubation of cultural and creative products through setting a program (it does not belong to special entrusted development) independently. After designing and making model successfully, the transferee can buy out the ownership of cultural and creative product in one time to get continuous R \& D expenditure or cultural and creative company can 
be entrusted for transformation. Cultural and creative products join in the joint development of creativity enterprises in the form of intellectual investment for the purpose of industrialization, which not only saves costs, but also reduces development time and improves work efficiency. The creative industry park of culture creativity companies, media and colleges \& universities can be entrusted to realize the industrial incubation of cultural and creative products. Industrialization extension can be realized by brand and capitalization path.

In both transfer \& authorization and joint development, intellectual property application and protection mechanism is used to industrialize cultural and creative products. It is the only way to accelerate cultural and creative industrialization and sustainable development by boosting the role of cultural and creative capital in market organization, ensuring cultural and creative capital can join in the shares of creative enterprises in the form of intelligent investment and exerting its driving effect on the real economy and virtual economy [10].

\subsection{Start Business via the Program}

Different from the traditional industries featured by intensive labor force and dominated by nature resources, soil, capital and machine, cultural and creative industry more relies on culture, knowledge, art and science \& technology. Cultural capital, intellectual property capital and technological capital are the core development factors of cultural and creative industry. To be specific, inter-disciplinary talents are the core driving force. Teams or individuals with core technical and creativity advantages could start business and then achieve industrialization success quickly by branding and capitalization. The idea also applies to young IT celebrities in the $21^{\text {st }}$ century.

Colleges and universities and local governments at all levels motivate and support the students who have excellent creative programs to start a business. Most graduates live near colleges and universities after their graduation, for the consideration of the broad boundary of cultural and creative industry, high integration, sufficient resources of colleges and universities such as humanistic, technical and education resources and open international environment. The above is beneficial to integrating resources at all aspects for business startup and setting up an open entrepreneur team. The aggregation becomes another feature of cultural and creative industry, either from the perspective of cultural art or economic management, technology and creativity. After the closed connection of creativity and modern technology, new products could be derived by modern industrial operation and new industry chain can be formed to upgrade manufacture industry. Information technology is advancing the development and upgrading of cultural and creative industry at an unprecedented speed.

\section{Conclusions}

Focusing on the incubation, industrialization path and correlation mechanism of cultural and creative products in colleges and universities, from the perspective 


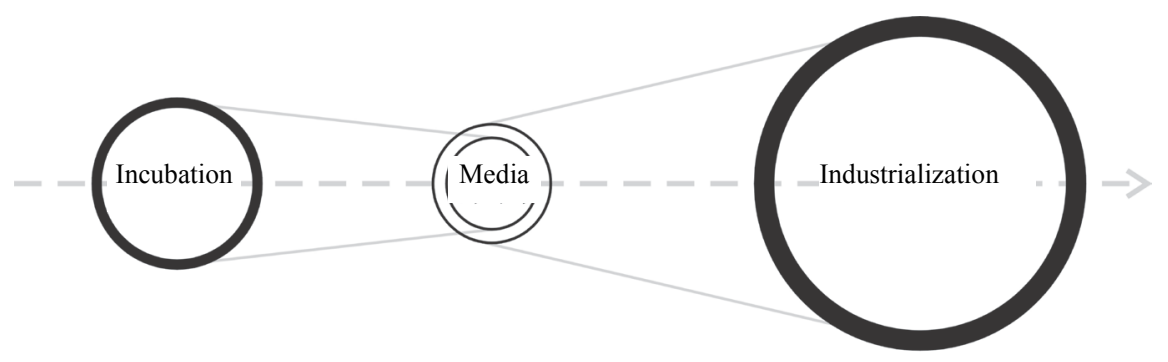

Figure 2. Schematic diagram for the connection and systematicness of incubation and industrialization path of cultural and creative industry.

of "public entrepreneurship and mass innovation", this paper puts forward feasible strategy aiming at the problems of incubation and industrialization of cultural and creative products in colleges and universities on the basis of analyzing the current cultural and creative industry in our country. As the upstream on the industrial chain of culture creativity, colleges and universities always focus on talent cultivation and academic research. As the downstream, market sticks to the principle of making profit. Their values are different in large degree. Therefore, colleges and universities need to build internal and external platforms, set up bridge and give full play to media (Figure 2). To establish the industrial ecology of culture creativity, on one hand, it is necessary to give full play to the superiority of culture creativity incubation in local colleges and universities; on the other hand, it is suggested to sufficiently apply teaching practice base including the media of creativity industry and the service platform of culture creativity industry built by government to offer the services of guide, exchange, incubation and popularization for the culture creativity entrepreneurship of students and teachers. The teaching in program system drives reform of education. The cooperation between school and enterprise can be encouraged to optimize and integrate the resources of government, enterprises and schools, stimulate the reform of higher education and accelerate the upgrading of the structure of culture creativity industry.

The culture creativity R \& D in colleges and universities is a part of the construction of Chinese culture's soft strength. At present, it is in the exploration stage and imitates others. There are few culture creativity brands and enterprises which exert great influence on mainstream culture and core value of the world. We need to carry forward the long history and culture of Chinese nation, introduce advanced creative design, apply modern scientific production technology, constantly improve the incubation and industrialization path of culture creativity products from theory to practice, cultivate inter-disciplinary talents, capture the opportunity of higher education reform stimulated by national economy transition and the development of culture creativity industry, transfer the strategic positioning of knowledge-based and skill-oriented talent cultivation to be innovation-oriented and creativity-oriented. Therefore, this paper gives theory and practical guidance for talent cultivation in culture creativity industry and deep implementation of national strategy of culture creativity. 


\section{Supporting Information}

This paper is the study result of the subject Study on the Incubation and industrialization of Cultural and Creative Products of Colleges and Universities in the Perspective of "Public Entrepreneurship and Mass Innovation" of Sichuan Research Center for Cultural Industry Development. (No: WHCY2017B05).

\section{Conflicts of Interest}

The author declares no conflicts of interest regarding the publication of this paper.

\section{References}

[1] General Office of the State Council of the People's Republic of China (2015) Opinions on Deepening the Reform of Innovation and Entrepreneurship Education in Colleges and Universities.

[2] Xu, L. and Liu, M. (2018) Construction of Innovation and Entrepreneurship Talent Cultivation Ecosystem in Culture Creativity Industry of Colleges and Universities. China Adult Education, No. 11, 70-72.

[3] Ye, H. (2017) The Problems of Talent Cultivation for Culture Creativity in Colleges and Universities. Co-Operative Economy \& Science, No. 12, 164-165.

[4] Jin, D. (2009) Perspective and Thinking of Creative Industry. Adpersonin, No. 3, 117.

[5] Yuan, Y. and Tu, Y. (2019) Exploration to Contemporary Cultural Creative Industry in Taiwan. Fujian Arts, No. 3, 24-29.

[6] Ma, C. (2019) Research on Innovative Talent Cultivation for Cultural Creative Industry in Colleges and Universities-Taking the Colleges and Universities in Jilin Province for Examples. Art Science and Technology, No. 6, 86-87.

[7] Dong, W. (2014) Research on the Operation Mechanism of Creative Industrialization. Ocean University of China, Qingdao, 153.

[8] Cai, X. (2019) The Competitive Edge of Emerging Strategic Cultural Creative Industry Developed in Taiwan. Xiamen Science \& Technology, No. 2, 22-23.

[9] Song, J. and Lin, C. (2019) The Development and Popularization of Cultural Creative Products in Colleges and Universities in "Internet+" Era. Public Communication of Science \& Technology, No. 6, 158-159.

[10] Zheng, H. (2011) The Industrialization Path Theory of Cultural Creativity. Journal of Shanghai Normal University (Philosophy and Social Sciences), No. 4, 85-94. 